\title{
Impact and effectiveness of transport policy measures for a renewable-based energy system
}

Venturini, G.; Karlsson, Kenneth; Münster, M.

Published in:
Energy Policy

Link to article, DOI:

10.1016/j.enpol.2019.110900

Publication date:

2019

Document Version

Peer reviewed version

Link back to DTU Orbit

Citation (APA):

Venturini, G., Karlsson, K., \& Münster, M. (2019). Impact and effectiveness of transport policy measures for a renewable-based energy system. Energy Policy, 133, [110900]. https://doi.org/10.1016/j.enpol.2019.110900

\section{General rights}

Copyright and moral rights for the publications made accessible in the public portal are retained by the authors and/or other copyright owners and it is a condition of accessing publications that users recognise and abide by the legal requirements associated with these rights.

- Users may download and print one copy of any publication from the public portal for the purpose of private study or research.

- You may not further distribute the material or use it for any profit-making activity or commercial gain

- You may freely distribute the URL identifying the publication in the public portal

If you believe that this document breaches copyright please contact us providing details, and we will remove access to the work immediately and investigate your claim. 


\section{Impact and effectiveness of transport policy measures for a renewable-based energy system}

Venturini, Giada; Karlsson, Kenneth Bernard; Münster, Marie

Published in:

Energy Policy

Publication date:

2021

Document Version

Peer reviewed version

Link back to DTU Orbit

Citation (APA):

Venturini, G., Karlsson, K. B., \& Münster, M. (Accepted/In press). Impact and effectiveness of transport policy measures for a renewable-based energy system. Energy Policy.

\section{General rights}

Copyright and moral rights for the publications made accessible in the public portal are retained by the authors and/or other copyright owners and it is a condition of accessing publications that users recognise and abide by the legal requirements associated with these rights.

- Users may download and print one copy of any publication from the public portal for the purpose of private study or research.

- You may not further distribute the material or use it for any profit-making activity or commercial gain

- You may freely distribute the URL identifying the publication in the public portal

If you believe that this document breaches copyright please contact us providing details, and we will remove access to the work immediately and investigate your claim. 


\title{
Impact and effectiveness of transport policy measures for a renewable-based energy system
}

\author{
Giada Venturini $\square^{\mathrm{a}, \mathrm{b}}$, Kenneth Karlsson ${ }^{\mathrm{a}}$, Marie Münster ${ }^{\mathrm{a}}$ \\ ${ }^{a}$ Department of Management Engineering, Technical University of Denmark, 2800 Kgs. Lyngby, Denmark \\ ${ }^{b}$ Danish Energy Agency, Carsten Niebuhrs Gade 43, 1577 Copenhagen, Denmark
}

\begin{abstract}
The unsustainable growth in global transport activity is straining planet's resources and ecosystems. Hence, there is a need to promote technological developments, regulatory instruments and social changes to reduce the impact of mobility demand on energy use and environment. The current paper aims at assessing the impact and effectiveness of transport policy measures in reaching emission reduction targets for the case of the integrated energy and transport system of Denmark. Our analysis of policy scenarios is performed in collaboration with experts, stakeholders and citizens, and facilitated by a newly developed Scenario Interface tool linked to the energy system model TIMESDK. Market signals, in the form of taxes on $\mathrm{CO}_{2}$ and fossil fuels, retain the highest impact in lowering the carbon emissions from the transport sector, while the promotion of Mobility-as-a-Service is the most cost-effective measure among those analysed. Finally, we discuss the implications of combining instruments into policy packages and emphasise the urgency of addressing technology and policy solutions for the maritime and aviation sectors.
\end{abstract}

Keywords: Transport, Policy analysis, Integrated energy system, Scenario, Stakeholder

\section{Introduction}

The continuous growth in global mobility demand, coupled with a long-lived dependence on fossil energy resources, poses a significant challenge in ensuring the future sustainability of the transport sector [1]. Transport activity accounts for $23 \%$ of the energy-related greenhouse gas (GHG) emissions at global level [2]. While the increase in population, income and trade contributes to the rise in energy demand for transport, limited alternative fuels, especially in the heavy-duty segments, along with lock-in effects in the fuel and transport infrastructure, have determined a slower pace in the transition to renewable sources with respect to other economic sectors $[3,4]$.

Strategies aiming at reducing the impact of transportation on energy consumption, GHG emissions and pollution cover technical, economic and social measures, which can be grouped in three overarching actions: promote active and public transport modes ("shift"); reduce commuting distances and the need to travel ("avoid"); increase efficiency and switch to low-carbon alternatives ("improve") $[5,6]$. Sustainable mobility can be achieved by interventions within technology, regulation, information and economy [7], further articulated into physical, soft or knowledge policies [8]. Moreover, demand management measures targeting lifestyle and users' behaviour [9, 10] should be assessed in combination with supply side solutions, e.g. promoting technology and infrastructure development, through careful design of targeted policy packages [7].

Email address: gve@ens.dk (Giada Venturini $₫)$ 
Evaluating the potential and implications of these actions in achieving the mitigation targets can be informed from quantitative assessment tools, such as integrated energy and transport system models $[11,12]$. On the other hand, the uncertainty around the future evolution of the energy and transport system, coupled with the difficulty of sufficiently capturing all relevant dimensions of reality in a quantitative model, can offset the usability of the analyses. To secure coherence and impact on policy-making, these limitations can be addressed by developing scenarios in a collaborative framework, where stakeholders' perspectives can be integrated to inform and support the quantitative modelling, through e.g. expert elicitation [13], multi-criteria analysis [14] and interactive tools [15]. A close dialogue with transport policy-making is indeed fundamental for identifying the suitable interventions to achieve sustainable mobility $[16,15]$ and energy systems $[17,18]$. This process can clarify implementation barriers, potential synergies, expected acceptability and effectiveness of policy instruments.

Within this framework, the present paper aims at offering a quantitative assessment of the impact and effectiveness of transport measures in reaching emission reduction targets for the case of the integrated energy and transport system of Denmark. A Scenario Interface tool, linked to the energy system model TIMES-DK, facilitates the participatory development and analysis of future scenarios, built as combination of technology and policy assumptions. After introducing the background for the case of the Danish energy and transport system in Section 2, the modelling framework and main data assumptions are described in Section 3. The development and definition of scenarios is illustrated in Section 4, while the results for single and combined measures are presented in Section 5 . Section 6 discusses modelling results and policy implications, drawing the conclusions in Section 6.3.

\section{Case study: the Danish energy and transport system}

In Denmark, energy and climate goals have characterised the political agenda since the 1970s, as to both ensure security of energy supply and cost-effectively comply with GHG emissions targets [19]. On the long run, Denmark aims at becoming completely independent of fossil fuels by 2050 [20], contributing to European [21] and international commitments [22] for a low-carbon society. To ensure a robust pathway to these long-term goals, Danish energy policy has traditionally been governed by energy policy agreements [23]. Moreover, since 2014, a climate law has been established to secure a continuous focus on climate policy, with recommendations provided by the Climate Council [24].

As a result, the Danish energy system has witnessed in recent years increasing investments in renewable energy, especially wind power, solar photovoltaic and bioenergy, coupled with energy efficiency measures both in industrial and residential sectors [25]. Renewable energy holds a total share of $35 \%$ in the primary energy consumption in 2017 [25], with a target of $55 \%$ in 2030, as established in the latest energy agreement [23].

The transport sector, accounting for $34 \%$ of the final energy use and $38 \%$ of the energy-related $\mathrm{CO}_{2}$ emissions in 2016 [26], is primarily dominated by the use of fossil fuels, with the largest segments being road and air transport. Battery electric and plug-in hybrid vehicles represent only $0.5 \%$ of the total passenger fleet in 2017, with an expected share of $7.4 \%$ in 2030 under business as usual conditions [25]. The private passenger sector is highly regulated through a set of taxes [27]: a vehicle registration tax (VRT) proportional to the investment cost and depending on the fuel efficiency, to be paid upon purchase; an ownership tax, based on the fuel efficiency and weight of the vehicle, paid twice a year; and fuel taxes, diversified per type of fuel (diesel, gasoline, electricity, LPG, natural gas). Furthermore, the European legislation both on fuel $[28,29]$ and vehicle efficiency standards [30] applies to the Danish context. In particular, with respect to biofuels, the current Danish legislation requires a 5.75\% volume blending requirement [31], with fuel standard E5 for gasoline and B7 for diesel. By 2020, the minimum share of advanced biofuels is raised to $0.5 \%$ and the maximum for food-based biofuels is set to $7 \%$.

Incentives to promote a low-carbon transport system have been mainly focusing on electro-mobility 
in the private sector $[32,20]$, as well as advanced biofuels and biomethane for the heavy transport [31]. Initiatives include pilot projects for the introduction and test of electric vehicles, the establishment of funds for recharging infrastructure [20], and founding partnerships for promoting the use of biomethane in freight and public transport [24].

At planning and political level, more focus has been set on promoting technology switch and energy efficiency measures, as means to reduce the impact of the transport sector on fuel consumption, emissions, congestion and local pollution. On the other hand, initiatives such as car sharing, car pooling, promotion of non-motorised modes, incentives to public transport through infrastructure investments and/or subsidies could also contribute to a sustainable transport system [33, 10]. Under the climate framework set by the European Commission for the period 2020-2030 [34], GHG emissions from the sectors outside the European Emission Trading Scheme (ETS), i.e. agriculture, residential and transport, should follow a reduction of minimum $30 \%$ with respect to 2005 levels. In Denmark, the emission reduction obligation in the non-ETS sectors has been set to 39\% [35].

In light of these national and European targets for the transport sector, the current study analyses the impact and effectiveness of a suite of transport and energy policy measures in contributing to a more sustainable transport sector for Denmark.

\section{Methodology}

The generation and analysis of transport policy scenarios is facilitated by a newly developed Scenario Interface tool coupled with the energy system model TIMES-DK. A series of scenario workshops with stakeholders, citizens and experts have been organised, with the purpose of creating and discussing future visions of the transport sector in Denmark, in the context of achieving a renewable-based energy system. For further details on the specifics of the stakeholder engagement process for this study, the reader can refer to [36].

\subsection{Modelling framework}

A variety of integrated energy and transport models exists, which adopt a bottom-up or hybrid modelling approach, thus allowing for a technology-rich representation of the transport sector [? ]. Such a disaggregated perspective strengthens the analysis and definition of targeted policy measures, possibly diversified by vehicle technology, fuel type, transport mode or consumer group. Moreover, optimization models can determine least-cost pathways to meet a specific policy goal under a range of scenario assumptions. This strength makes them useful decision support tools in assessing the long-term effects of policies and measures in the integrated energy and transport system.

Considering these model characteristics, the energy system model TIMES-DK, belonging to the TIMES model family [37], was applied and further developed within this study. TIMES-DK is a techno-economic, partial equilibrium model assuming full foresight and perfectly competitive markets, with technological and economic projections until 2050. In particular, the model provides a system assessment of the whole energy sector for Denmark, including the representation of energy technologies and their competition in supplying the electricity, heat and transport demands, under the overall objective of total cost minimisation [38]. The total system cost $\mathrm{Obj}$ (Eq. 1) discounted to the reference year $Y_{R}$ at the discount rate $d$ represents the sum of annual investment costs $I_{n} v_{r, y}$, fixed and variable operation and maintenance costs $O \& M_{r, y}$, import costs $I m p_{r, y}$ and export revenues $\operatorname{Exp}_{r, y}$ for each model region $r$ and year $y$. If included in the analysis, i.e. private-economic assessment, taxes $T a x_{r, y}$ and subsidies $S u b_{r, y}$ are addends of the objective function.

$$
O b j=\sum_{r \in R} \sum_{y \in Y}\left(\operatorname{Inv}_{r, y}+O \& M_{r, y}+\operatorname{Imp}_{r, y}-\operatorname{Exp}_{r, y}+\operatorname{Tax}_{r, y}-S u b_{r, y}\right) *(1+d)^{Y_{R}-y}
$$




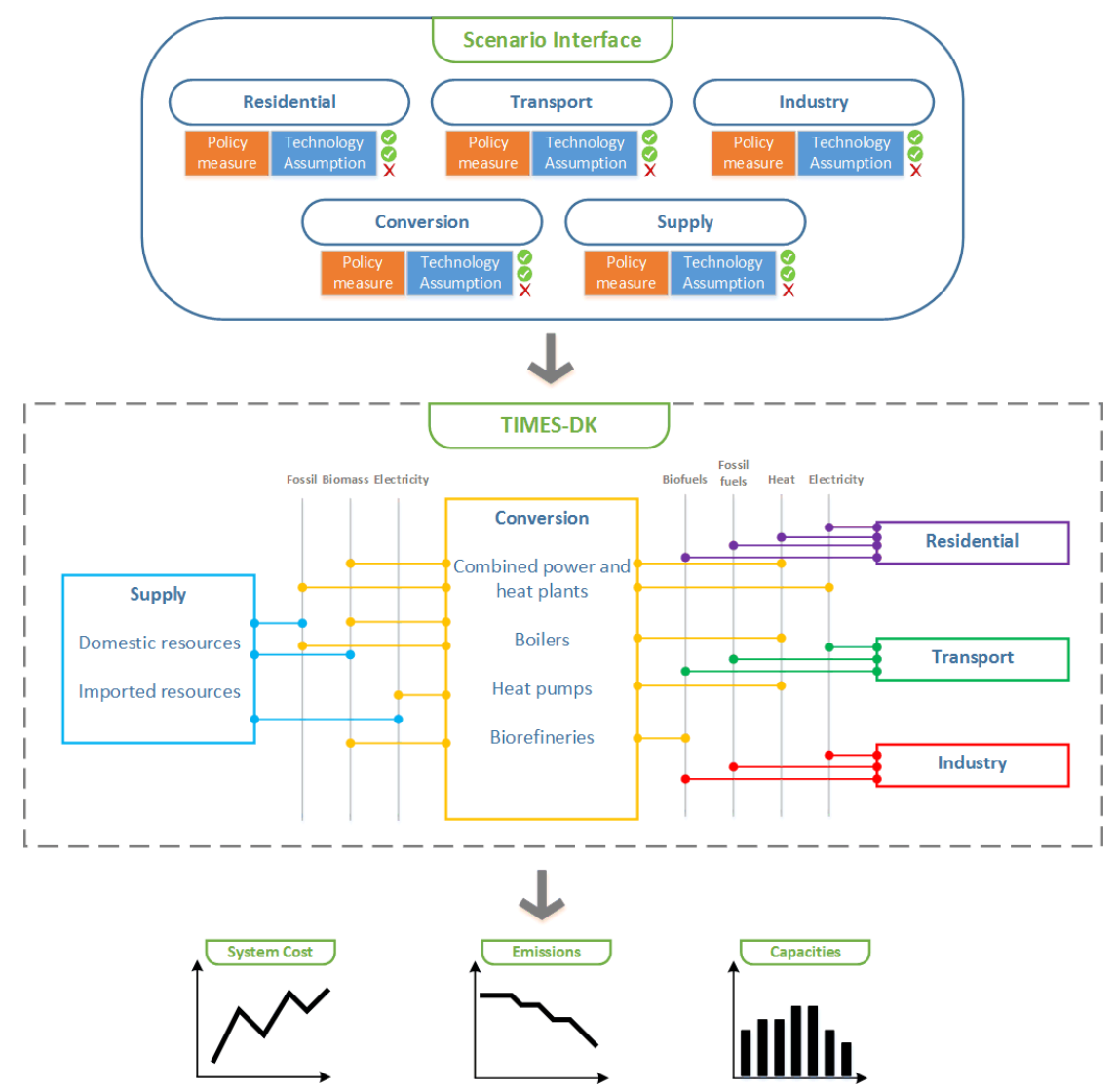

Figure 1: Modelling framework adopted for the creation of transport scenarios.

The inclusion of the most important end-use sectors of the economy, i.e. industry, residential, and transport, allows examining the interplay between supply and end-use sectors from a system perspective. In particular, a whole system assessment can reveal synergy and competition dynamics, as the resources, such as fuels, heat and electricity, are generated and shared across sectors.

For the purpose of this study, a Scenario Interface tool has been developed in Microsoft Excel ${ }^{\circledR} 2016$, gathering the main input assumptions of TIMES-DK, with the aim of supporting the creation of energy and transport scenarios by a non-modeller audience, typically stakeholders and policy makers involved in foresight projects. The tool allows the user to select a variety of parameters and constraints for the energy system by using drop-down menus and tick boxes.

Background information and descriptions of choices in the form of pop-up comments guide the user along the scenario creation in a self-learning environment. Moreover, graphs illustrate the baseline projections for, e.g. transport demands and renewable energy production and capacity, as to provide information on the reference scenario (see Appendix A for further details).

The tool communicates the scenario choices directly with the model TIMES-DK (Figure 1), which compiles the run and executes the optimization algorithm in GAMS. Currently, the link with TIMESDK is achieved through the construction of input data tables, later read by TIMES-DK's data management interface software (VEDA-FE ${ }^{1}$ ). Further development is undergoing for parsing the scenario data directly in GAMS, thus allowing to bypass the data management software VEDA-FE and speeding up the scenario creation.

In particular, the tool is organised around the sectors modelled in TIMES-DK, i.e. supply, conversion, industry, residential and transport, as well as on general policy targets. For each of these, a specific section details a number of assumptions and constraints, which the user can modify when creating a scenario. Choices are gathered around two main types for each section: policy measures and tech-

\footnotetext{
${ }^{1}$ http://support.kanors-emr.org/
} 
nology assumptions (Figure 1). For instance, in the transport sector, policy measures include taxes adjustments, while technology assumptions comprise infrastructure development and penetration of electric bikes. During the workshops herein reported, focus has been given to the sections related to policy targets, supply and transport, as the main object of study was discussing and creating visions for the future Danish transport system [36].

\subsection{Data}

This section describes the main data inputs used to represent the transport sector in TIMES-DK, as well as the measures analysed within the integrated energy and transport system. For a complete overview of the data and assumptions used in TIMES-DK, including data sources and model calibration for all sectors, the reader can refer to the model documentation [38].

\subsubsection{Representation of the transport sector}

In TIMES-DK, the transport sector includes both passenger and freight, with further disaggregation into several modes. Passenger transport covers air, ferry, private car, bus, coach, rail (metro, train, light rail), 2-wheeler (motorcycle and moped) and non-motorised modes (bike and walk). Freight comprises aviation, shipping and the inland modes van, truck and train [39].

The TIMES-DK model version used for this study contains an advanced representation of the inland transport sector [39], in which modal shift can occur, based not only on the levelised costs of the modes, but also on mode speed and transport infrastructure requirements. This latter parameter ensures that the level of infrastructure accommodates the mobility demand for each mode or group of modes, with three main transport infrastructure types included, i.e. road, bike lanes, and railways. Yearly travel demands (Figure 2) need to be satisfied at the minimum cost, while complying with an assigned travel time budget (the latter condition valid for the inland passenger demands). The set of technologies competing for satisfying the demands represent vehicles, each characterised by techno-economic parameters, i.e. investment cost, operation and maintenance cost, fuel efficiency, mileage, lifetime, travelling time, and occupancy/load factor. As a convention, the annual demands for international aviation and maritime transport are calculated by attributing, for each trip, half of the travelled kilometres to Denmark and half to the other country.

Fuel supply chains, both fossil and biofuels, are modelled from production to distribution, along with fuel imports and exports [40]. Fuel consumption in vehicles is associated with $\mathrm{CO}_{2}$ emission factors $(\mathrm{kg} \mathrm{CO} / \mathrm{GJ}$ fuel). Furthermore, the motor vehicle taxes discussed in Section 2 are included in TIMES-DK, diversified by vehicle and fuel type, while assuming average vehicle sizes for each technology included.

\subsubsection{Transport measures analysed}

The selection of measures to be analysed in the adopted modelling framework follow from a literature review combined with inputs gathered during scenario workshops [36]. In these workshops, stakeholders, interested citizens and experts in the energy and transport fields were invited to outline and discuss the most uncertain and impacting parameters affecting the transport sector in the context of living up to Denmark's 2050 goals and achieving a 100\% renewable-based energy system. The purposive selection of the stakeholders was performed with the aim of including representatives from a variety of public and private organizations in the energy and transport domain in Denmark. Another important objective was to include stakeholders with a wide range of perspectives on issues related to energy and transport in Denmark, with varying expertise and knowledge. For a complete overview of the stakeholder involvement process and scenario development study, the reader is invited to refer to the complementary article [36]. 


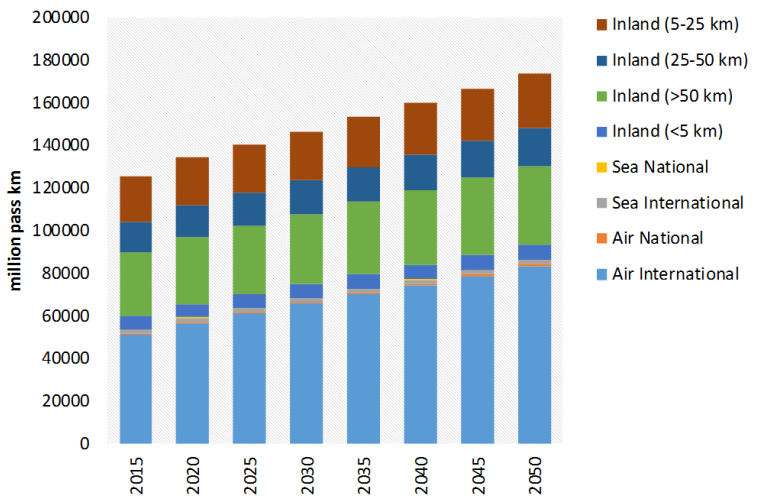

(a)

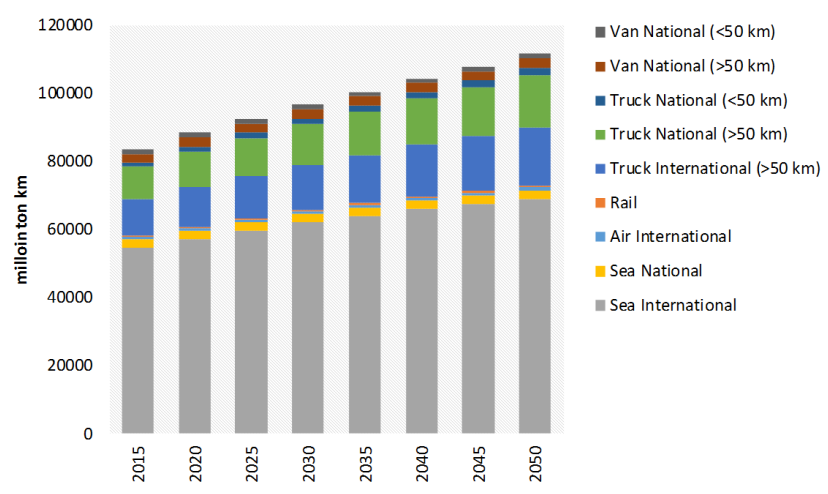

(b)

Figure 2: Projections of passenger (a) and freight (b) transport demands for Denmark.

In a first stage, a combination of technology and policy measures were elicited from the stakeholder engagement work and later included in the Scenario Interface tool. In a second stage, the Scenario Interface tool was adopted for the development of consistent energy and transport scenarios, built as combinations of the different policy measures and technology assumptions.

Table 1 lists the measures affecting the transport sector included in this study, as a result of the performed scenario exercises. As explained in Section 3.1, the parameters analysed include both transport policy measures (e.g. vehicle registration tax), assumptions on technology (e.g. share of e-bikes), travellers' behaviour (e.g. car occupancy) and infrastructure development (e.g. railways infrastructure). Each measure is analysed on a range of values, bounded at the extremes by literature values and choices of stakeholders. For instance, the parameter car occupancy, at the one end, represents a case in which autonomous mobility is widespread (average of 1 person/vehicle), while, at the other end, it portrays a case where Mobility-as-a-Service (MaaS) is largely adopted in the form of car sharing and car pooling (average of 2 person/vehicle). Additional behavioural measures comprise the choice of no-travel embedded in the measure of teleworking, resulting in reduced commuting travel demand, and the level of adoption of electric bikes. Infrastructure parameters include the further development of bike lanes, investments in high-speed rail for long-distance passenger transport, and the development of a more interconnected public transport system resulting in reduced waiting times, thus travelling times for users [8]. On the other hand, transport regulatory measures include a ban on Internal Combustion Engine (ICE) vehicles, with a range of enforcement years [27]; adjustments of fuel taxes applied to transport vehicles, both fossil and electricity; exemption of the vehicle registration tax for plug-in hybrid electric vehicles (PHEV), battery electric vehicles (BEV), and both PHEV and BEV.

\begin{tabular}{|c|c|c|c|c|c|c|c|c|}
\hline Measure & Category & & Val & le Range & & Unit & Year & Quantification \\
\hline Bike infrastructure & Level of investment & $+50 \%$ & $+100 \%$ & & & million pass-km/year & 2030 & $\mathrm{~L}$ \\
\hline E-bikes & Share on bikes total & $1 \%$ & $10 \%$ & $25 \%$ & $50 \%$ & $\%$ & 2030 & $\mathrm{E}+\mathrm{S}$ \\
\hline Railways infrastructure & Average speed & 120 & 150 & & & $\mathrm{~km} / \mathrm{h}$ & 2030 & $\mathrm{~L}$ \\
\hline Public transport & Travelling time & $-1 \%$ & $-10 \%$ & & & $\%$ & 2025 & $\mathrm{~L}$ \\
\hline Car occupancy & Autonomous cars/ MaaS & 1 & 2 & & & person/vehicle & 2025 & $\mathrm{~L}+\mathrm{S}$ \\
\hline Teleworking & Commuting demand & $-1 \%$ & $-5 \%$ & & & $\%$ & 2030 & $\mathrm{~L}$ \\
\hline ICE cars & ICE ban & 2025 & 2030 & 2040 & 2050 & Year enforced & - & $\mathrm{L}+\mathrm{S}$ \\
\hline Fossil fuel & Fuel tax & $+10 \%$ & $+50 \%$ & $+100 \%$ & & $\%$ & 2025 & $\mathrm{E}+\mathrm{S}$ \\
\hline Electricity & Fuel tax & $-10 \%$ & $-50 \%$ & $-100 \%$ & & $\%$ & 2025 & $\mathrm{E}+\mathrm{S}$ \\
\hline Vehicle registration tax & Tax exemption & PHEV & $\mathrm{BEV}$ & PHEV \& BEV & & Vehicle class & 2025 & $\mathrm{~L}+\mathrm{S}$ \\
\hline
\end{tabular}

Table 1: Transport measures analysed. L: Literature review; S: Stakeholders input; E: Estimate. 


\subsection{Energy measures analysed}

To analyse possible system synergies achieved through cross-sectoral policies, as well as to assess the feasibility of supplying the transport sector with the domestic renewable energy resources, measures encompassing the whole energy system are included in the study, as illustrated in Table 2. Restricting the access respectively to imported biomass and biofuels, under a range of starting years, allows to evaluate the level of resource-dependence from abroad. The imposition of a tax on $\mathrm{CO}_{2}$ emissions from both ETS (i.e. power and heat, large industrial plants) and non-ETS sectors (i.e. transport and residential) is considered with three variants: the first case assumes a constant tax across years, equal to the level in 2015 [41]; the second case applies the quota price valid within the ETS market also to non-ETS sectors, using price projections from the Danish Energy Agency [42]; the last case adopts the $2^{\circ} \mathrm{C}$ scenario from Nordic Energy Technology Perspectives [43] for both ETS and non-ETS emissions. To comply with Denmark's goal of becoming independent of fossil fuels by 2050 [20], we implement a banning measure imposing a complete phase-out of fossil fuels from the sectors power and heat, residential and industry, starting from 2040.

\begin{tabular}{|c|c|c|c|c|c|c|c|c|}
\hline Measure & Category & & Value Rang & & & Unit & Year & Quantification \\
\hline Biomass & No import & 2025 & 2030 & 2040 & 2050 & Year enforced & - & $\mathrm{E}+\mathrm{S}$ \\
\hline Biofuels & No import & 2025 & 2030 & 2040 & 2050 & Year enforced & - & $\mathrm{E}+\mathrm{S}$ \\
\hline $\mathrm{CO}_{2}$ emissions & $\mathrm{CO}_{2} \operatorname{tax}$ & $\begin{array}{l}\text { ETS: } 8 \text { - NETS: } 23 \\
\text { ETS: } 8 \text { - NETS: } 23\end{array}$ & $\begin{array}{l}\text { ETS: } 23 \text { - NETS: } 23 \\
\text { ETS: } 43 \text { - NETS: } 43\end{array}$ & $\begin{array}{c}\text { ETS: } 30 \text { - NETS: } 30 \\
\text { ETS: } 130 \text { - NETS: } 130\end{array}$ & & $\begin{array}{l}€ / \text { ton } \\
€ / \text { ton }\end{array}$ & $\begin{array}{l}2025 \\
2050\end{array}$ & $\mathrm{~L}+\mathrm{S}$ \\
\hline Fossil fuels & Phase-out & Power\&Heat & Residential & Industry & & Sector & 2040 & $\mathrm{~L}+\mathrm{S}$ \\
\hline
\end{tabular}

Table 2: Energy system measures analysed. L: Literature review; S: Stakeholders input; E: Estimate.

\section{Scenario definition}

To compare the impact of the different transport and energy measures, these are firstly applied oneat-a-time onto a Business As Usual $(B A U)$ private-economic scenario, representing a frozen policy scenario of the Danish energy system, including taxes and subsidies in all sectors. The $B A U$ case performs a long-term optimization of the Danish energy system, with exogenous assumptions on price developments, technologies potentials and decommissioning. Exogenous future fuel prices are aligned with Danish projections [44], while electricity prices regulating the trade with neighbouring countries, as well as transmission lines capacities, are based on data from the Danish Transmission System Operator (TSO) [45] and European TSO [46].

Furthermore, two other reference cases are presented: $B A U_{-} S E$, a socio-economic $B A U$, i.e. without taxes and subsidies applied in the energy system, and CO2_SE, representing a carbon-constrained socio-economic scenario. The latter case contains a cumulative bound on $\mathrm{CO}_{2}$ emissions from all sectors, in compliance with a maximum temperature increase of $1.5^{\circ} \mathrm{C}$ compared to pre-industrial levels, with $66 \%-50 \%$ level of confidence $[47,22]$. As a common agreement on the attribution method for allocating the climate mitigation burden among world nations does not yet exist, a variety of approaches could be applied to attribute Denmark's share of the global carbon budget $C O_{2 w}$ [47], including effort-sharing criteria such as responsibility, capability, equality, and cost-effectiveness [48]. In this study, the concepts of inertia, i.e. emissions, and equity, i.e. population, are equally distributed, as in the method proposed by [49] (Eq. 2).

$$
C O_{2 i}=C O_{2 w} \cdot\left(w_{p o p} \cdot \frac{p o p_{i}}{p o p_{w}}+w_{e m i s} \cdot \frac{e m i s_{i}}{e m i s_{w}}\right)
$$

The carbon budget $C \mathrm{O}_{2 i}$ for each country $i$ is proportional to population $p_{0} p_{i}$ and emissions emis $_{i}$ ratios on the respective global values pop $_{w}$ and emis $_{w}$ (2011 levels used herein [50]), with weight factors respectively $w_{p o p}$ and $w_{\text {emis }}$, both assumed 0.5 in this study. The resulting carbon budget for 


\begin{tabular}{|c|c|c|c|c|}
\hline & New Mobility & Electrification & Market-driven & Sea\&Air \\
\hline Bike infrastructure & - & - & - & - \\
\hline E-bikes & $50 \%$ & - & - & - \\
\hline Railways infrastructure & - & - & - & - \\
\hline Public transport & - & - & - & - \\
\hline Car occupancy & 2 & - & - & - \\
\hline Teleworking & $5 \%$ & - & - & - \\
\hline ICE ban & - & - & 2030 & - \\
\hline Fossil fuel tax & - & $+100 \%$ & - & - \\
\hline Electricity tax & - & $-100 \%$ & - & - \\
\hline Vehicle registration tax & - & PHEV \& BEV & - & - \\
\hline Biomass no-import & - & - & - & - \\
\hline Biofuels no-import & - & - & - & - \\
\hline $\mathrm{CO}_{2}$ tax & - & - & $130 € /$ ton & - \\
\hline Fossil fuels phase-out & - & Power\&Heat & - & Maritime\&Aviation \\
\hline
\end{tabular}

Table 3: Scenario definition - combined transport and energy measures.

Denmark from 2015 lies within the range of 400-860 million tonnes of $\mathrm{CO}_{2}$.

The transport-focused scenarios are built as a combination of the single transport and energy measures. In particular, we analyse three theme-focused scenarios, New Mobility, Electrification and Market-driven (Table 3), informed by the scenario choices made by workshop participants, and further refined to contain the most impacting measures (Section 5.2). Considering their impact on the total transport demand and fuel consumption (Figure 2), we analyse one additional scenario, SeaEAir, focusing on the decarbonisation of the aviation and maritime transport sectors. In this last case, the only analysed measure is the imposition of a ban on the use of fossil fuels in these transport modes, enforced from 2040.

\section{Results}

\subsection{Reference scenarios}

In the three reference scenarios, the future fuel consumption from the Danish transport sector decreases from the current levels (Figure 3), primarily through an increased share of electricity in the fuel mix for the inland transport segment. Furthermore, biofuels such as biodiesel, bioethanol and biokerosene, progressively substitute their fossil counterparts. For all the reference scenarios, while both biodiesel (36 PJ in 2050) and bioethanol (8 PJ in 2050) are domestically produced from biomass resources, e.g. rapeseed oil, sugarbeet and agricultural residues, the biokerosene supplying the aviation segment is mainly imported from abroad (37 PJ in BAU and 46 PJ in CO2_SE in 2050).

No major differences can be observed between the private-economic and the socio-economic base cases, except for the phase-out of diesel from 2040 in $B A U_{-} S E$. In the carbon-constrained scenario CO2_SE, a switch from kerosene to biokerosene in the aviation sector along with a greater blending of biodiesel into diesel within the inland segment results in significantly lower fossil emissions, respectively reduced by $68 \%$ in 2040 and $73 \%$ in 2050, with respect to the $B A U$ scenario.

Within the whole Danish energy system, the transport sector accounts for $42 \%$ of the total $\mathrm{CO}_{2}$ emissions in 2015, maintaining the same share in 2050 in the $B A U$ scenario (Figure 4). However, while the inland transport segment is responsible for the largest part of transport-related emissions in 2015 (74\%), the aviation and maritime sectors are the main emitters in 2050, respectively accounting for $73 \%$ and $19 \%$ of the total transport emissions. Industry and waste incineration are the other remaining sectors where decarbonisation options are more scarce or too expensive. Therefore, 


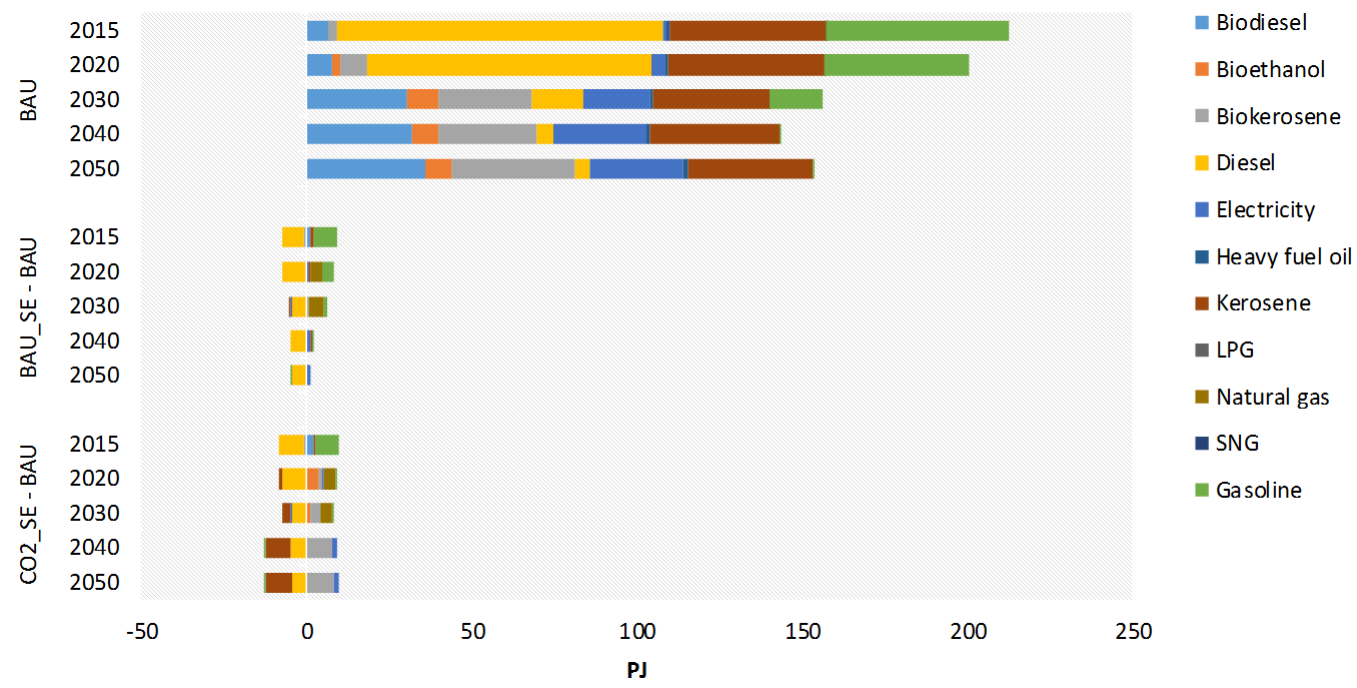

Figure 3: Fuel consumption from the Danish transport sector. Deviations from the $B A U$ are reported for the scenarios $B A U_{-} S E$ and CO2_SE.

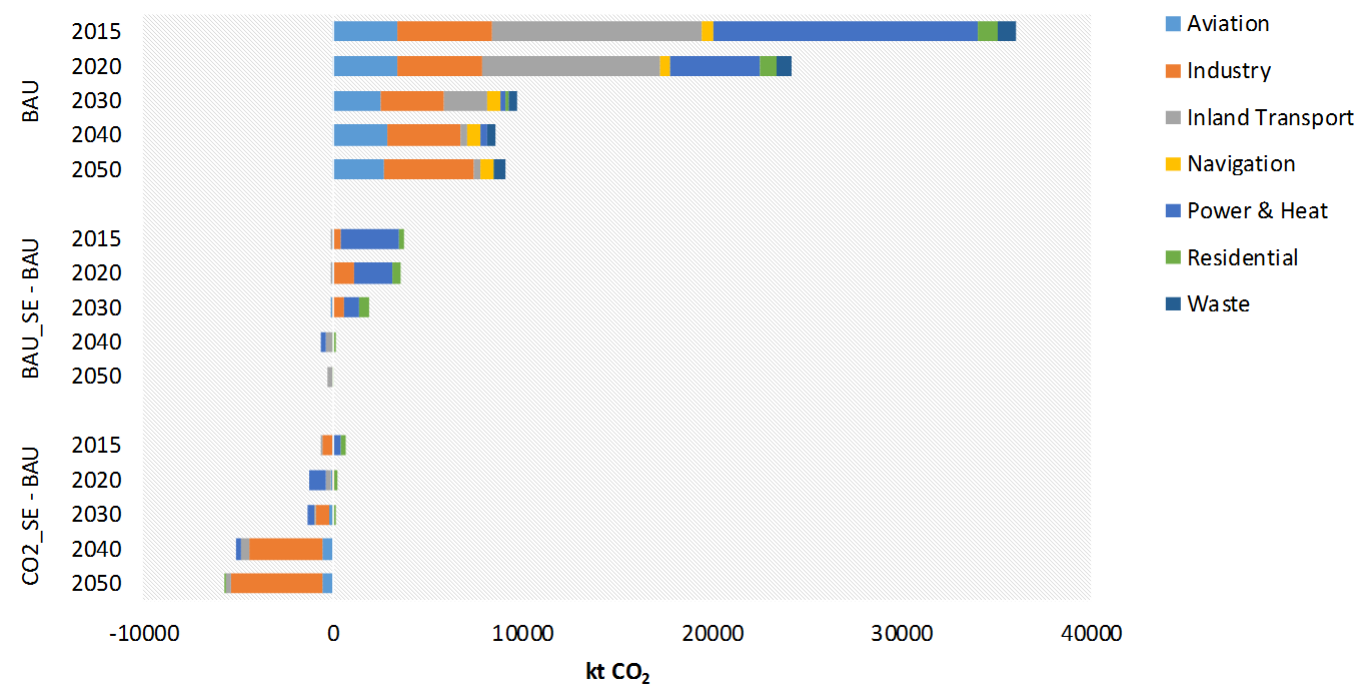

Figure 4: $\mathrm{CO}_{2}$ emissions from the Danish energy system by sector. Deviations from the $B A U$ are reported for the scenarios BAU_SE and CO2_SE.

increasing focus should be set on evaluating and supporting solutions targeting technologies, policies, users' and firms' behaviour in these most challenging (and often less regarded) segments of the energy system.

Under the carbon-constrained socio-economic scenario, CO2_SE, the industry sectors become progressively more renewable-based towards 2050, through a fuel switch from diesel, coal and natural gas to biomass and electricity. The modal split across the inland transport modes (Figure 5) remains stable across the three reference scenarios, except for a slight increase in the share of buses in the mid-years in the BAU_SE and CO2_SE cases, at the expenses of private cars. The reason is to be found in the parameters affecting modal choice, i.e. mode cost and travel time, which are not changed nor affected in the reference scenarios. Car holds the largest segment, covering $74 \%$ of the travel demand in 2050. In the absence of policies targeting modal shift, most modes present constant shares across time, while the bike share increases from $3 \%$ in 2015 to $7 \%$ in 2050 , and the light rail slightly moves from $2 \%$ to $3 \%$ in the period $2015-2050$. 


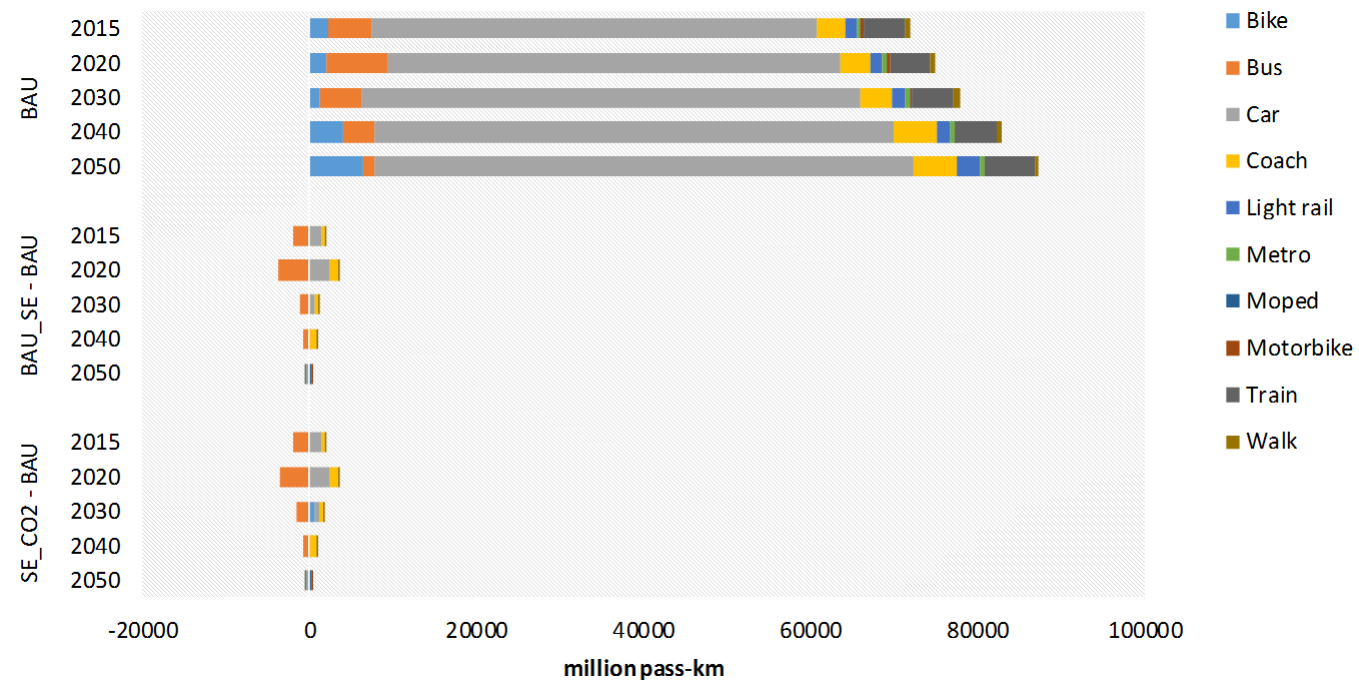

Figure 5: Modal split of the Danish inland transport sector. Deviations from the $B A U$ are reported for the scenarios $B A U_{-} S E$ and CO2_SE.

\subsection{Transport and energy measures - single effects}

The effect of the single transport and energy measures applied to the $B A U$ scenario is presented in Figure 6 , which illustrates their relative effectiveness, i.e. the total energy system cost including all sectors, and impact, i.e. the cumulative $\mathrm{CO}_{2}$ emissions from the transport sector. The scatter plot displays with a coloured symbol the measures with the highest impact on system cost and emissions, while the remaining measures, having a minor effect on the assessment parameters, are all positioned within the dotted circle in the centre of the graph. As a reference, the cumulative $\mathrm{CO}_{2}$ emissions from the transport sector (2020-2050) amount to $209 \mathrm{Mt}$, for a total system cost of 413740 million $€$ in the $B A U$ case.

One of the most effective measures in reducing the emissions from the transport sector are the fuel taxes, respectively an exemption of the fuel tax for electricity and a doubling of the taxes applied to gasoline and diesel consumption in vehicles. This taxation measure retains a large influence on transport emissions, as it affects all inland vehicle technologies. On the other hand, lifting the VRT for BEVs and PHEVs does little in terms of reducing emissions from the private passenger segment, as the car stock is composed by low-carbon vehicles already in the $B A U$ scenario. To this respect, the optimal car stock determined by TIMES-DK might contain an optimistic introduction of BEVs and PHEVs, due to the assumed average vehicle sizes and static vehicle retirement profiles.

The imposition of a carbon tax on $\mathrm{CO}_{2}$ emissions from all sectors, including transport, holds the largest effect on shifting the transport sector towards renewable sources and transport modes: the lower emissions from the transport sector are mainly explained by a fuel switch to biofuels in the aviation sector, and to electricity in the bus and coach segment.

The development of teleworking, embracing the options of working from home and choosing not to travel, has an impact on the long-distance commuting demand, with resulting positive consequences for the emission budget. As expected, transport emissions can be lowered also through a higher car occupancy, as less vehicles are required to deliver the same transport demand. On the other hand, when assuming an occupancy factor equal to 1 for passenger cars as a proxy for a greater adoption of autonomous vehicles, we observed that the emissions from the transport sector are also significantly reduced. The reason for this counter intuitive result derives from the trade-off between infrastructure investments, i.e. in road and rail, and technology investments in the inland transport segment. While car dominates the mode shares in the $B A U$ scenario, covering $72-77 \%$ of the inland transport demand in the period 2020-2050, a modal shift occurs from cars towards buses and trains when applying a lower car occupancy factor. As the reduced occupancy would require expensive 


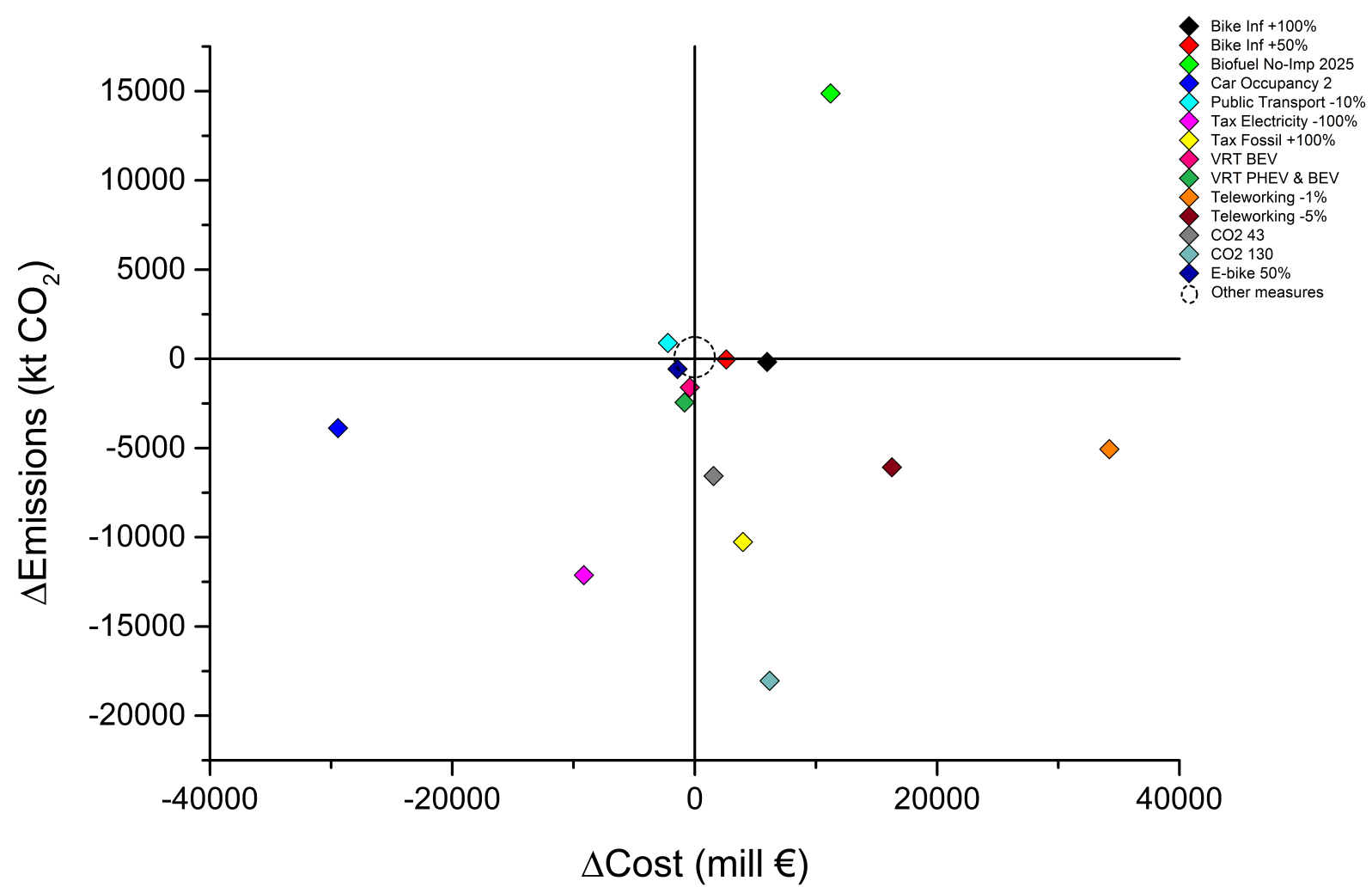

Figure 6: Relative effects of single transport and energy measures on total system cost and transport-related emissions compared to the BAU scenario (cumulative effects for the period 2020-2050).

investments in road infrastructure to accommodate the increased number of vehicles on the roads, investments in railways infrastructure are preferred in a least-cost solution.

With a $50 \%$ share of e-bikes, a larger part of the medium-distance inland transport demand is covered by the bike mode ( $4 \%$ against $2 \%$ in the $B A U$, as an average over the period 2030-2050), as electric bikes allow longer distance trips, in the range of $25-50 \mathrm{~km}$. As a result, the transport sector witnesses a slight decrease in its $\mathrm{CO}_{2}$ emissions, i.e. by $2 \%$ with respect to the $B A U$ case.

Higher car occupancy factors and adjustments in the fuel taxation bring about a positive impact also on the total system cost. Furthermore, a more interconnected public transport system resulting in lower travelling times slightly reduces the total system cost, as lower infrastructure investments are required to satisfy the same level of mobility demand. Conversely, the most expensive measures include the scenarios with increased investments in bike infrastructure and the teleworking cases, where part of the long-distance inland demands shifts to train, with consequent higher investments in railway infrastructure. As previously observed for the case of low car occupancy, infrastructure represents a significant cost component in the total transport cost, partly explaining the slow pace of transition for this sector (see also Section 5.3).

Limiting the imports of biofuels as early as in 2025 causes a rise in transport-related emissions because biofuels are partly substituted with fossil fuels, in particular for gasoline and kerosene. The reason is to be found in the absence of constraints on import and use of fossil fuels in transport. As a result, in the private passenger segment, the biofuel limit scenario witnesses a slower uptake of battery electric vehicles in favour of more plug-in hybrids, with respect to the $B A U$ case. Reducing the travelling time for public buses prompts, as expected, a modal shift from bikes and cars towards buses. However, this results in a slight increase in transport-related $\mathrm{CO}_{2}$ emissions $(0.5 \%$ higher than $B A U)$, because of the increased diesel consumption in the years 2020-2025. 


\subsection{Transport and energy measures - combined effects}

The combined effectiveness and impact of the single transport and energy measures, aggregated in the three theme-focused scenarios, is presented in Figure 7. Among the three stakeholders' cases, the Electrification scenario realises the highest emission reduction, through the implementation of a regulatory framework promoting simultaneously low-carbon electricity production and electromobility, especially in the private passenger segment. A stronger introduction of BEVs is moved up to the year 2020 with respect to 2030 in the BAU scenario, at the expenses of PHEVs, due to the higher fuel taxes on gasoline. As a result, the car fleet is fully electrified in 2050.

The lower emissions in the Market-driven scenario are primarily explained by the introduction of a high carbon tax [43], applied to fossil fuel consumption in all sectors. This results in an increased share of biofuels in the aviation sector starting from 2030, reaching a biokerosene blending of $60 \%$ in 2050. Moreover, a fuel switch occurs from diesel to electricity in buses and coaches moving towards 2050. While no relevant modal shift takes place in these two scenarios, in the New Mobility case, the high car occupancy generates a shift from bikes and coaches towards cars, which deliver $79 \%$ of the total travel demand in 2050 (against $72 \%$ in 2020), yet at lower transport-related emissions. Furthermore, the 5\% lower commuting demand, due to the assumed teleworking, contributes to reducing the total fuel consumption in the inland transport sector.

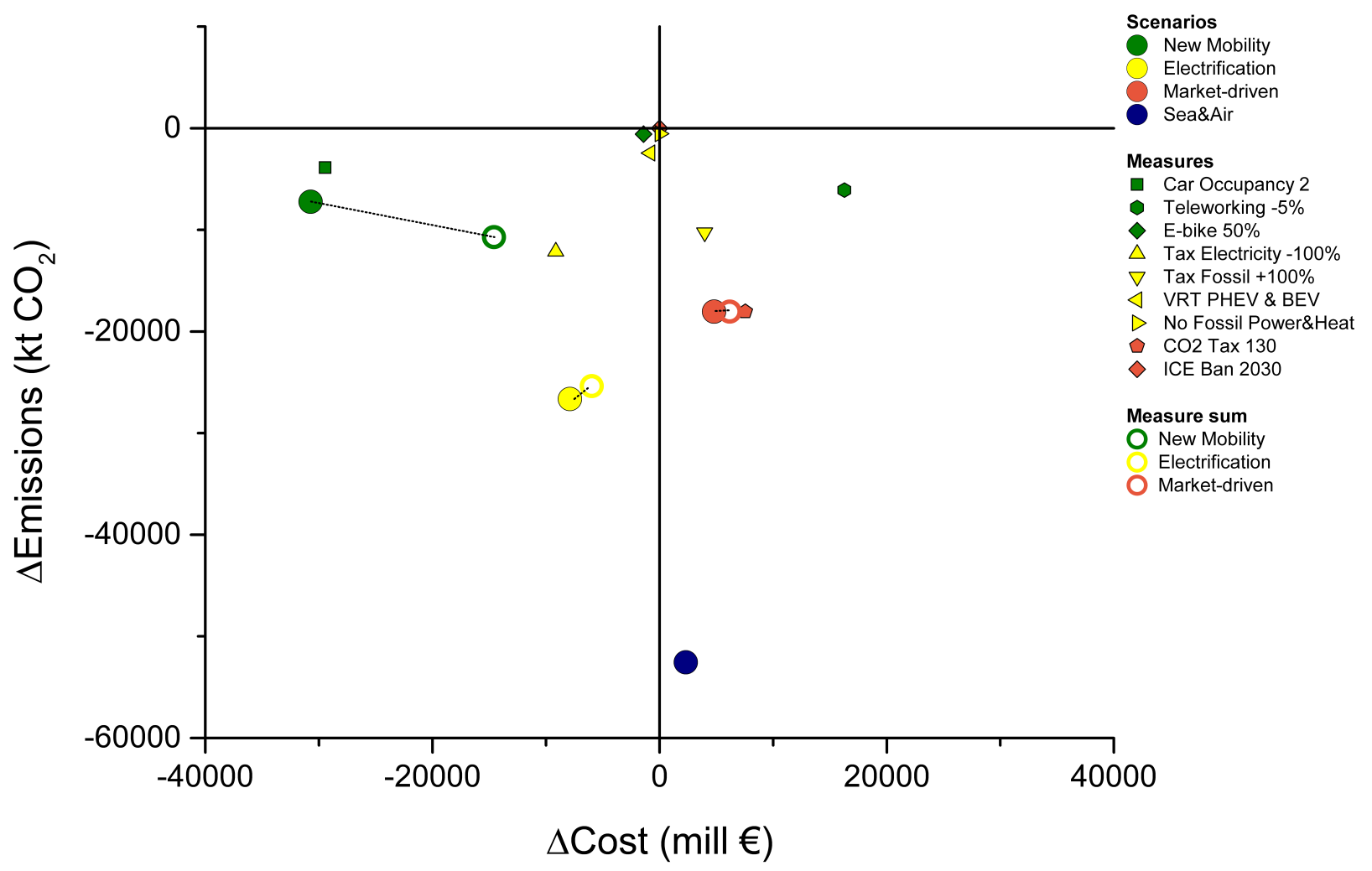

Figure 7: Relative effects of combination scenarios on total system cost and transport-related emissions compared to the $B A U$ scenario (cumulative effects for the period 2020-2050).

The scenario SeaEAir highlights the importance of a fuel switch in the aviation and maritime sectors for reaching the decarbonisation targets, in the absence of reductions in travel demands or modal shift, e.g. from air to train for domestic flights. Within air transport, a shift occurs from kerosene to biokerosene, as this was the only low-carbon option considered in the model. Other aviation propellants, e.g. electricity for short-distance flights, have not been included at this stage. In the maritime sector, heavy fuel oil is progressively phased out and replaced by biodiesel. Although the analysis on 
future options for maritime fuels should be broadened, this scenario underlines the consequences of not addressing the transition to low-carbon options in these energy-intensive transport segments. In fact, the SeaEGAir case lowers the cumulative transport-related fossil emissions by $25 \%$ compared to the $B A U$.

The significance of transport infrastructure costs is highlighted in Figure 8, which summarises the breakdown of annual transport costs across the analysed scenarios for three reference years. The transition to a more sustainable transport sector requires investments in transport technologies in all scenarios in the period 2015-2050, due to the upgrade to new and more fuel-efficient transport vehicles. On the other hand, this is accompanied by a general decrease in fuel costs and taxes, owing to the higher penetration of electricity as a transport fuel. Starting from 2025, the New Mobility case realises a lower total transport cost with respect to the other scenarios, due to the more efficient use of transport vehicles through the assumed high car occupancy factor.

Fuel costs, including fuel infrastructure, hold an increasingly marginal share of the total transport cost, equivalent to $5 \%$ on average in 2050 . On the other hand, transport infrastructure, mainly railways and marginally cycling lanes, covers approximately $40 \%$ of the total annual transport cost in 2050 for all scenarios, except for New Mobility. As previously discussed, the New Mobility case does not require additional investments in transport infrastructure, as the existing infrastructure can sufficiently accommodate the whole inland transport demand.

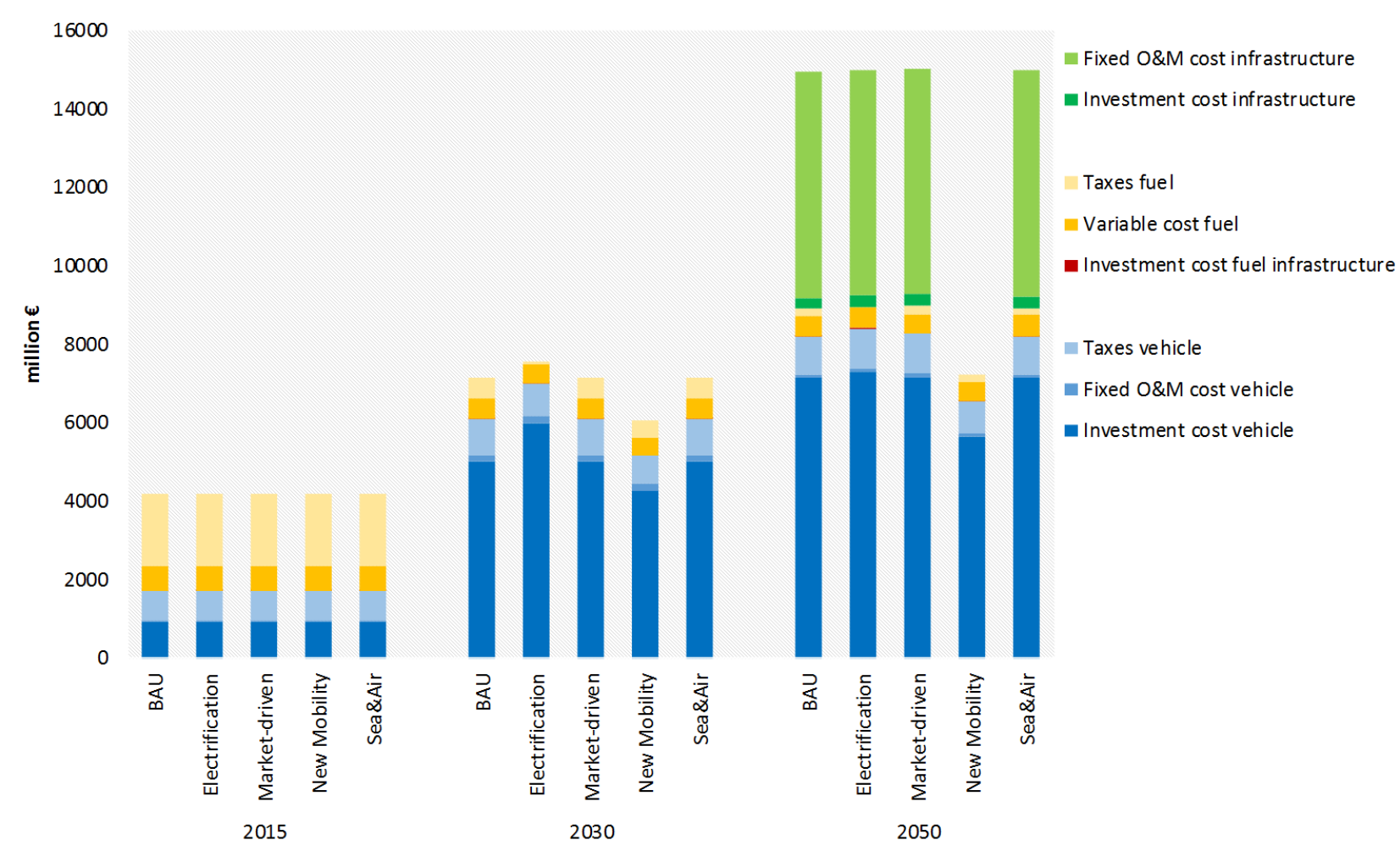

Figure 8: Overview of total annual costs in the transport sector by scenario for three reference years

\section{Conclusion and Policy Implications}

\subsection{Policy implications}

Considering the energy and transport measures in isolation, market signals in the form of taxes or subsidies, i.e. fuel and $\mathrm{CO}_{2}$ taxes, represent the most effective measures for emissions reduction in the transport sector. On the other hand, the imposition of a ban on ICE vehicles has a minor impact on 
total emissions, as the car stock is already composed of mostly hybrids or electric vehicles from 2035 in the $B A U$ scenario, where a continuation of the current VRT reduction on purchases of electric vehicles is assumed. Similarly, a ban on fossil fuels in the industry or residential sector does not affect the transport sector directly, since no cross-sectoral competition arises over resources, e.g. biofuels. Moreover, the measures targeting fuel switch are far more effective at reducing emissions than the instruments designed for modal shift, e.g. decreasing travelling time or investing in rail infrastructure. However, the aggregated geographical resolution and the simplified representation of modal shift in TIMES-DK possibly hinder a deeper analysis of the potential of specific parameters and policies targeting modal shift, e.g. policies closely related to urban planning and land use patterns, such as parking reforms, dedicated bus lanes, and road pricing.

When combining the single measures into policy packages, a more complete picture of the policy interaction within the energy and transport system is obtained. The hollow circles in Figure 7 locate the sum of the effects of the single measures considered in each combination scenario. The proximity between the model results of the combination scenarios, i.e. the full circles, and the calculated combined effect of the single measures, i.e. the hollow circles, can provide an indication on the existence of synergies and complementarities across the single policy instruments [51]. The Electrification scenario, combining regulation of the power sector, fuel taxes and vehicles registration taxes, shows additivity of the single policy instruments from both an economic and environmental perspective, i.e. the benefit from the use of all the instruments in a policy package is similar to the benefit of each instrument in isolation [51]. In the Market-driven case, no particular pattern can be observed, as the application of a carbon tax retains the major impact on cost and emissions. On the other hand, the carbon tax positively impacts the rest of the energy system, reducing the emissions from the residential and industry sectors by $74 \mathrm{Mt}$ in the period 2020-2050.

The scenario New Mobility reveals a synergy among the implemented measures when considering the impact on the system cost, as the simultaneous use of the three instruments provides a greater benefit than the three measures taken in isolation. In particular, the combined effect of a greater adoption of ride- and car-sharing, together with the increased possibility of teleworking is explained by the reduced infrastructure requirements for road and rail to accommodate the passenger travel demand. The same synergy effect cannot be observed for the impact on emissions, as e.g. the assumption on higher occupancy for cars neutralises the introduction of more e-bikes in the system. When designing policy packages, these dynamics should be considered to obtain the desired system performance, here measured on system cost and transport emissions. Policy integration has in fact proved effective when applying a combination of push measures, e.g. discouraging car use through higher taxes, and pull measures, e.g. improvement of the level of service of public transport [8].

In terms of effectiveness, the macro-economic effects and implications of the actual policy implementation are not included in the total system cost, as computed in the model TIMES-DK. However, in practice, the feasibility of the analysed measures depends on several factors, such as political negotiations, market barriers and public acceptability. Market and regulatory measures, such as a $\mathrm{CO}_{2} \operatorname{tax}$ on fossil fuel consumption, can follow from national or international directives. The European ETS is based on a cap-and-trade principle and it covers $\mathrm{CO}_{2}, \mathrm{~N}_{2} \mathrm{O}$ and PFC (Perfluorinated compound) emissions from power plants and manufacturing installations, as well as airlines travelling between European airports $[52,53]$. In Denmark, the ETS partially overlaps with a national $\mathrm{CO}_{2}$ tax applied to the consumption of fossil fuels, with large exemptions to, e.g. large-scale heat and power plants, energy-intensive industries, international aviation and international shipping [54]. The application of the $\mathrm{CO}_{2}$ tax to the whole transport sector, as proposed in this present study, would require an explicit extension of the current system. European standards also set a minimum level for taxes on motor fuels in EU member states [55]. In this respect, literature studies have reported a uniform country-independent negative elasticity for the price of motor fuel in the range of -0.3 to -0.8 on travel demand [56], stressing on the effectiveness of this measure in addressing fuel (and possibly mode) shift in transport. Policies operating on the vehicle registration tax, often in combination with scrapping schemes, have proven successful in speeding-up the adoption of low-carbon vehicles, especially in the 
private passenger segment, both internationally and in the Nordic context [32]. Moreover, future studies could investigate the impact of a strong power market, such as the Nordpool in the Northern Europe, on laying down favourable conditions for the widespread adoption of electro-mobility (e.g. by offering grid stability, demand response and power storage solutions).

Investments in transport infrastructure display a local-dependent success rate with high effectiveness in densely populated urban areas, with notable examples in London, where large investments in bus service infrastructure and safety, coupled with the enforcement of a road toll ring, have shifted a large share of the commuting trips from private car to public transport [8]. Moreover, the improvement of walking and cycling lanes, as well as the physical integration of railway stations and walking and cycling facilities is associated to an increase in the share of non-motorised modes in cities like Copenhagen in Denmark [8]. Finally, soft measures, such as the promotion of MaaS and teleworking, require a critical user mass and the identification of potential user groups through attitude-based segmentation [10] to design targeted information, awareness and marketing campaigns.

\subsection{Methodological insights}

The facilitated participatory definition of energy and transport policy scenarios allowed analysing and pinpointing the set of relevant measures, both taken in isolation and as part of policy packages, which are effective at reducing transport emissions in the Danish context. The inclusion of and interaction with stakeholders supported mutual learning and shared understanding along the process [36]. From the modelling side, experts' inputs contributed to the validation of assumptions and in determining the feasible spectrum of policy change, i.e. the range along which a specific parameter was tested. From the policy-making side, the co-development of scenarios raised awareness around the critical aspects of the energy system from a technical and environmental perspective, e.g. the urgency of addressing the most impacting segments of the transport sector. The ability of a model to work as "boundary object", thus performing a communicating and binding role between the academic and institutional communities has been already identified by [57], within environmental policies, and by [18], for the case of the MARKAL model in the UK context. Moreover, an inclusive and comprehensive screening of policy measures allows for decision-making to be based on a more robust and democratic process, which accounts for future uncertainties and multiple perspectives [14]. On the other hand, the process requires several iteration steps, as to integrate additional policy measures in the modelling framework, accordingly to the pace of the political decisions, or to recalibrate model parameters, e.g. a change to a tax scheme. Still, the mutual learning is inevitably a lengthy and intricate journey, in that a constant reciprocal communication needs to inform on the model capabilities and limitations in capturing measures and trends, as well as on the relevance of addressing the components not covered in the model with alternative assessment methods.

\subsection{Conclusions}

This study analysed the impact and effectiveness of measures promoting technological development, regulatory instruments and social changes for the case of the integrated energy and transport system of Denmark. We addressed a variety of measures, both in isolation and in combination within policy packages, in cost-effectively reducing transport-related $\mathrm{CO}_{2}$ emissions. Market signals, in the form of taxes on $\mathrm{CO}_{2}$ and fossil fuels, retain the highest impact in lowering the carbon emissions from the transport sector. On the other hand, the promotion of MaaS with associated higher utilisation rates of passenger vehicles is the most cost-effective measure among those analysed. Furthermore, the New Mobility scenario, targeting behavioural changes through the promotion of MaaS, teleworking and increased adoption of e-bikes, illustrates cost synergies from the combination of the different measures.

The application of a Scenario Interface tool allowed integrating stakeholders, citizens and experts in 
the field, thus benefiting both the validation of model assumptions and the creation of consistent and policy-relevant scenarios. Moreover, the participatory scenario development and analysis supported a shared understanding of pathways and system implications, as the workshop participants could observe the effects of their scenario choices on the modelling results.

The employed modelling framework harnesses the strength of energy system models like TIMES-DK in portraying policy interactions across the whole system, thus highlighting the need to address the transition to sustainable transport through the design of coherent policy packages. On the other hand, local-specific measures, e.g. parking reforms or road pricing, could be analysed with more geographically detailed tools. Similarly, qualitative methods exploring transport users' behaviour and preferences might better assess the effects and implications of soft policies, e.g. information campaigns on eco-driving. Finally, considering the impact of the maritime and aviation sectors on fuel consumption and GHG emissions, future research could expand their technological representation in integrated energy and transport system models, and investigate demand drivers and policy measures for these transport segments.

\section{Acknowledgements}

The authors would like to thank Meiken Hansen, Lars Klüver and Henrik Gudmundsson for organising the workshops with citizens and stakeholders, extending the thanks to all the workshop participants. The first author would like to particularly acknowledge Helge Larsen for providing technical assistance during the development of the Scenario Interface tool. The work reported in this article has been undertaken within the COMETS project, financed by the Innovation Fund Denmark (grant number 4106-00033B).

\section{References}

[1] J. Eliasson, S. Proost, Is sustainable transport policy sustainable?, Transport Policy 37 (2015) 92-100. doi:10.1016/j.tranpol.2014.09.010. 1

[2] International Energy Agency, World Energy Statistics and Balances 2015 (2015). 1

[3] J.-M. Cayla, N. Maizi, Integrating household behavior and heterogeneity into the TIMES-Households model, Applied Energy 139 (2015) 56-67. doi:10.1016/j.apenergy.2014.11.015. 1

[4] M. S. Jorgensen, U. Jorgensen, J. S. Jensen, Navigations and governance in the Danish energy transition reflecting changing Arenas of Development, controversies and policy mixes, Energy Research and Social Science 33 (2017) 173-185. doi:10.1016/j.erss.2017.09.034. 1

[5] International Energy Agency, Energy Technology Perspectives (2012). doi:10.1787/energy ${ }_{t}$ ech-2012-en. 1

[6] D. Banister, The sustainable mobility paradigm, Transport Policy 15 (2) (2008) 73-80. doi:10.1016/j.tranpol.2007.10.005. 1

[7] K. Nakamura, Y. Hayashi, Strategies and instruments for low-carbon urban transport: An international review on trends and effects, Transport Policy 29 (2013) 264-274. doi:10.1016/j.tranpol.2012.07.003. 1

[8] G. Santos, H. Behrendt, A. Teytelboym, Part II: Policy instruments for sustainable road transport, Research in Transportation Economics 28 (1) (2010) 46-91. doi:10.1016/j.retrec.2010.03.002. 1, 6, 14, 15

[9] C. Brand, J. Anable, C. Morton, Lifestyle, efficiency and limits: modelling transport energy and emissions using a socio-technical approach, Energy Efficiencydoi:10.1007/s12053-018-9678-9. 1

[10] S. Grischkat, M. Hunecke, S. Böhler, S. Haustein, Potential for the reduction of greenhouse gas emissions through the use of mobility services, Transport Policy 35 (2014) 295-303. doi:10.1016/j.tranpol.2014.06.007. 1, 3, 15 
[11] G. Venturini, J. Tattini, E. Mulholland, B. Ó Gallachóir, Improvements in the representation of behaviour in integrated energy and transport models, International Journal of Sustainable Transportationdoi:10.1080/15568318.2018.1466220. 2

[12] R. Gerboni, D. Grosso, A. Carpignano, B. D. Chiara, Linking energy and transport models to support policy making, Energy Policy 111 (2017) 336-345. 2

[13] S. Pye, F. G. Li, A. Petersen, O. Broad, W. McDowall, J. Price, W. Usher, Assessing qualitative and quantitative dimensions of uncertainty in energy modelling for policy support in the United Kingdom, Energy Research and Social Science 46 (2018) 332-344. doi:10.1016/j.erss.2018.07.028. 2

[14] K. Kowalski, S. Stagl, R. Madlener, I. Omann, Sustainable energy futures: Methodological challenges in combining scenarios and participatory multi-criteria analysis, European Journal of Operational Research 197 (3) (2009) 1063-1074. doi:10.1016/j.ejor.2007.12.049. 2, 15

[15] R. Hickman, S. Saxena, D. Banister, O. Ashiru, Examining transport futures with scenario analysis and MCA, Transportation Research Part A - Policy and Practice 46 (3) (2012) 560-575. doi:10.1016/j.tra.2011.11.006. 2

[16] J. Stephenson, S. Spector, D. Hopkins, A. McCarthy, Deep interventions for a sustainable transport future, Transportation Research Part D - Transport and Environment 61 (2018) 356-372. doi:10.1016/j.trd.2017.06.031. 2

[17] S. Mathy, M. Fink, R. Bibas, Rethinking the role of scenarios: Participatory scripting of low-carbon scenarios for France, Energy Policy 77 (2015) 176-190. doi:10.1016/j.enpol.2014.11.002. 2

[18] P. G. Taylor, P. Upham, W. McDowall, D. Christopherson, Energy model, boundary object and societal lens: 35 years of the MARKAL model in the UK, Energy Research and Social Science 4 (C) (2014) 32-41. doi:10.1016/j.erss.2014.08.007. 2, 15

[19] Danish Energy Agency, Denmark's Energy Timeline. Main events in the energy field (in Danish) (2016). 2

[20] The Danish Government, Energy Strategy 2050 - from coal, oil and gas to green energy. Summary (2011). $2,3,7$

[21] European Commission, Communication from the Commission to the European Parliament, the Council, the European Economic and Social Committee and the Committee of the Regions. Energy Roadmap 2050 (2011). 2

[22] UNFCCC, Report of the Conference of the Parties serving as the meeting of the Parties to the Kyoto Protocol on its eleventh session, held in Paris from 30 November to 13 December 2015. Addendum. Part two: Action taken by the Conference of the Parties serving as the meeting of the Parties to the Kyoto Protocol at its eleventh session. (2016). 2, 7

[23] The Danish Government, Energy Agreement (in Danish) (2018). 2

[24] The Climate Council, Transition Towards 2030. Building Blocks for a Low-Carbon Society. Main conclusions (2017). 2, 3

[25] Danish Energy Agency, Denmark's Energy and Climate Outlook 2018. Baseline Scenario Projection Towards 2030 with Existing Measures (Frozen Policy) (2018). 2

[26] Danish Energy Agency, Energy Statistics 2016 (in Danish) (2016). 2

[27] J. Tattini, E. Mulholland, G. Venturini, M. Ahanchian, M. Gargiulo, O. Balyk, K. B. Karlsson, A LongTerm Strategy to Decarbonise the Danish Inland Passenger Transport Sector, Lecture Notes in Energy 64 (2018) 137-153. doi:10.1007/978-3-319-74424-7. 2, 6

[28] European Parliament, Council of the European Union, Directive 2009/30/EC of the European Parliament and of the Council of 23 April 2009 amending Directive 98/70/EC as regards the specification of petrol, diesel and gas-oil and introducing a mechanism to monitor and reduce greenhouse gas emissions and amending Council Directive 1999/32/EC as regards the specification of fuel used by inland waterway vessels and repealing Directive 93/12/EEC (Text with EEA relevance) (2009). 2 
[29] European Parliament, Council of the European Union, Directive 2009/28/EC of the European Parliament and of the Council of 23 April 2009 on the promotion of the use of energy from renewable sources and amending and subsequently repealing Directives 2001/77/EC and 2003/30/EC (Text with EEA relevance) (2009). 2

[30] European Parliament, Council of the European Union, Regulation (EC) No 443/2009 of the European Parliament and of the Council of 23 April 2009 setting emission performance standards for new passenger cars as part of the Community's integrated approach to reduce CO2 emissions from light-duty vehicles (Text with EEA relevance) (2014). 2

[31] Danish Energy Agency, Analysis of alternative options for achieving the 2020 renewable target for transport (in Danish) (2015). 2, 3

[32] International Energy Agency, Nordic EV Outlook 2018. Insights from leaders in electric mobility (2018). doi:10.1787/9789264293229-en. 3, 15

[33] Metroselskabet and Hovedstadens Letbane, Megatrends. The future of collective transport in the metropolitan area (in Danish) (2017). 3

[34] European Commission, Communication from the Commission to the European Parliament, the Council, the European Economic and Social Committee and the Committee of the Regions. A policy framework for climate and energy in the period from 2020 to 2030 (2014). 3

[35] European Commission, Regulation (EU) 2018/842 of the European Parliament and of the Council of 30 May 2018 on binding annual greenhouse gas emission reductions by Member States from 2021 to 2030 contributing to climate action to meet commitments under the Paris Agreement and amending Regulation (EU) No 525/2013 (Text with EEA relevance) (2018). 3

[36] G. Venturini, M. Hansen, P. D. Andersen, Linking narratives and energy system modelling in transport scenarios: A participatory perspective from Denmark, Energy Research and Social Science 52 (2019) 204-220. doi:10.1016/j.erss.2019.01.019. 3, 5, 15

[37] R. Loulou, G. Goldstein, A. Kanudia, A. Lettila, U. Remme, Documentation for the TIMES Model Part I: TIMES Concepts and Theory (2016). 3

[38] O. Balyk, K. S. Andersen, S. Dockweiler, M. Gargiulo, K. Karlsson, R. Næraa, S. Petrović, J. Tattini, L. B. Termansen, G. Venturini, TIMES-DK: technology-rich multi-sectoral optimisation model of the Danish energy system, Energy Strategy Reviews 23 (2019) 13-22. doi:10.1016/j.esr.2018.11.003. 3, 5

[39] J. Tattini, M. Gargiulo, K. Karlsson, Reaching carbon neutral transport sector in Denmark - Evidence from the incorporation of modal shift into the TIMES energy system modeling framework, Energy Policy 113 (2018) 571-583. doi:10.1016/j.enpol.2017.11.013. 5

[40] G. Venturini, A. Pizarro-Alonso, M. Münster, How to maximise the value of residual biomass resources: The case of straw in Denmark, Applied Energy 250 (2019) 369-388. doi:10.1016/j.apenergy.2019.04.166. 5

[41] International Energy Agency, World Energy Outlook 2016 (2016). doi:10.1787/weo-2016-en. 7

[42] Danish Energy Agency, Baseline Scenario Projection 2017 (in Danish) (2017). 7

[43] International Energy Agency, Nordic Energy Technology Perspectives 2016. Cities, flexibility and pathways to carbon-neutrality (2016). doi:10.1787/9789264257665-en. 7, 12

[44] Danish Energy Agency, Socio-economic calculations for energy prices and emissions (in Danish) (2017). 7

[45] Energinet.dk, Energy Data Service, accessed on 31/01/2018 (2018).

URL https://www.energidataservice.dk/en/ 7

[46] ENTSO-E, ENTSO-E Transparency Platform, accessed on 31/01/2018 (2018).

URL https://transparency.entsoe.eu/ 7 
[47] IPCC, Climate Change 2014: Synthesis Report. Contribution of Working Groups I, II and III to the Fifth Assessment Report of the Intergovernmental Panel on Climate Change, Geneva, Switzerland (2014). 7

[48] N. Hohne, M. Den Elzen, D. Escalante, Regional GHG reduction targets based on effort sharing: a comparison of studies, Climate Policy 14 (1) (2014) 122-147. doi:10.1080/14693062.2014.849452. 7

[49] M. R. Raupach, S. J. Davis, G. P. Peters, R. M. Andrew, J. G. Canadell, P. Ciais, P. Friedlingstein, F. Jotzo, D. P. van Vuuren, C. Le Quere, Sharing a quota on cumulative carbon emissions, Nature Climate Change 4 (10) (2014) 873-879. doi:10.1038/NCLIMATE2384. 7

[50] World Bank Group, Data Catalog, Accessed on 31-01-2018 (2018). 7

[51] A. D. May, C. Kelly, S. Shepherd, The principles of integration in urban transport strategies, Transport Policy 13 (4) (2006) 319-327. doi:10.1016/j.tranpol.2005.12.005. 14

[52] E. Narassimhan, K. S. Gallagher, S. Koester, J. R. Alejo, Carbon pricing in practice: a review of existing emissions trading systems, Climate Policy 18 (8) (2018) 967-991. doi:10.1080/14693062.2018.1467827. 14

[53] European Commission, Report from the Commission to the European Parliament and the Council: Report on the Functioning of the European Carbon Market. (2017). 14

[54] Danish Ministry of Taxation, $\mathrm{CO}_{2}$ Tax Act (In Danish), http://www.skm.dk/skattetal/satser/satser-ogbeloebsgraenser/co2-afgiftsloven. Accessed on 06-09-2018. (2017). 14

[55] Council of the European Union, Council Directive 2003/96/EC of 27 October 2003 restructuring the Community framework for the taxation of energy products and electricity (Text with EEA relevance) (2003). 14

[56] R. Elvik, F. Ramjerdi, A comparative analysis of the effects of economic policy instruments in promoting environmentally sustainable transport, Transport Policy 33 (2014) 89-95. doi:10.1016/j.tranpol.2014.02.025. 14

[57] C. E. Van Daalen, L. Dresen, M. A. Janssen, The roles of computer models in the environmental policy life cycle, Environmental Science and Policy 5 (3) (2002) 221-231. doi:10.1016/S1462-9011(02)00040-0. 15 